\title{
On the Amount of Phosphoric Acid in the Sea-Water off Plymouth Sound. II.
}

\author{
By \\ Donald J. Matthews.
}

With one Figure in the Text.

In a previous paper* the writer gave the results of the determination of the phosphates in sea-water, by means of Pouget and Chouchak's reagent, on a number of samples collected between September 13, 1915, and February 5, 1916, at the Knap Buoy, half a mile outside the breakwater at Plymouth.

The analyses have been continued so as to cover a period of sixteen months and show a large seasonal variation.

The method is described in detail in the previous paper, and consists in throwing down the phosphoric acid with iron and an alkali, treating with nitric acid, and determining the amount colorimetrically in the Dubosq apparatus after adding nitromolybdate of strychnine. A few modifications have been made and are described below.

In the first place, as the pressure of other work made it impossible to examine all samples immediately after collection, they were sterilised as soon as taken with toluol or chloroform. Toluol was perfectly satisfactory, but the chloroform in some cases threw down a precipitate on standing, and the absence of figures for July, August, November and December, 1916, is due to the loss of samples from this cause. If the sample is allowed to stand without previous sterilisation the phosphates decrease and may be entirely removed in a few weeks.

The standard phosphate solution contained $0.003 \mathrm{mg}$. of $\mathrm{P}_{2} \mathrm{O}_{5}$ in one cubic centimetre, and was made up in approximately decinormal nitric acid to prevent the growth of moulds.

For the precipitation of the iron, sodium carbonate was used instead of ammonia and ammonium chloride; $1 \mathrm{ccm}$. of $2 \mathrm{~N}$ solution for $1 \mathrm{ccm}$. of iron solution was sufficient to more than neutralise the excess acid of the latter.

In some instances the iron precipitate was greasy and was difficult

* Matthews, D. J., "On the Amount of Phosphoric Acid in the Sea-Water off Plymouth Sound." This Journal, xi., No. 1, p. 122, March, 1916. 
to dissolve off the paper completely, so the following method was adopted. Five cubic centimetres of strong hydrochloric acid were poured into the beaker in which precipitation had taken place and distributed over the walls to dissolve any iron ; then $10 \mathrm{ccm}$. of water were added, the beaker was warmed for a few minutes, and the hot dilute acid was allowed to drop on to the filter paper by means of a small pipette provided with a rubber-teat head. 'The beaker and paper were well washed and the latter incinerated in a platinum crucible; the ash was dissolved in a little strong hydrochloric acid and added to the rest of the solution, which was then evaporated to dryness on the water-bath; the chlorides were converted to nitrates by evaporation to dryness with $10 \mathrm{ccm}$. of the dilute nitric acid, taken up in more nitric acid, using $7 \mathrm{ccm}$. of $25 \%$ by volume if the final bulk was to be $50 \mathrm{ccm}$. The analysis was then carried out as described in the previous paper. In an extreme case the dirty residue on the paper was found to contain $0.0024 \mathrm{mg}$. of $\mathrm{P}_{2} \mathrm{O}_{5}$. The origin of the greasy matter is unknown; it may be due to the drainage from the port, or, on the other hand, it may be the volatile oily substance which so often renders the distillate turbid when sea-water is boiled with an alkali for the determination of ammonia.

It was mentioned in the earlier paper that the amount of phosphates found was increased if the water was previously oxidised with a permanganate. Attempts to find a suitable method for determining this excess phosphorus have been only partly successful. It is necessary to use strong oxidising substances which do not interfere with subsequent operations and are easily purified. In the end the following process was adopted. From $200 \mathrm{ccm}$. to $400 \mathrm{ccm}$. of the water were evaporated in a porcelain basin holding nearly $200 \mathrm{ccm}$. until the bulk of the salts had separated; then $10 \mathrm{ccm}$. or $20 \mathrm{ccm}$. of strong nitric acid were added, according to the amount of sample taken, the dish was covered, and heating continued until the evolution of brown fumes had ceased. The cover was removed and the evaporation was continued to dryness; the dish was then heated over an argand burner until the salts were in gentle fusion and the nitrates of the earths were decomposed with evolution of brown fumes.

The dish was allowed to cool and the salts were dissolved by warming for an hour with $150 \mathrm{ccm}$. of water and $1 \mathrm{ccm}$. of strong hydrochloric acid. Iron was added and $5 \mathrm{ccm}$. of $2 \mathrm{~N}$ sodium carbonate solution and the analysis completed as before. There is danger of the porcelain being attacked unless it is very carefully heated, and unless it is certain that it gives up no phosphates under this treatment it would probably be better to use fused silica basins.

The blank on the reagents used in the analyses reported in the previous 


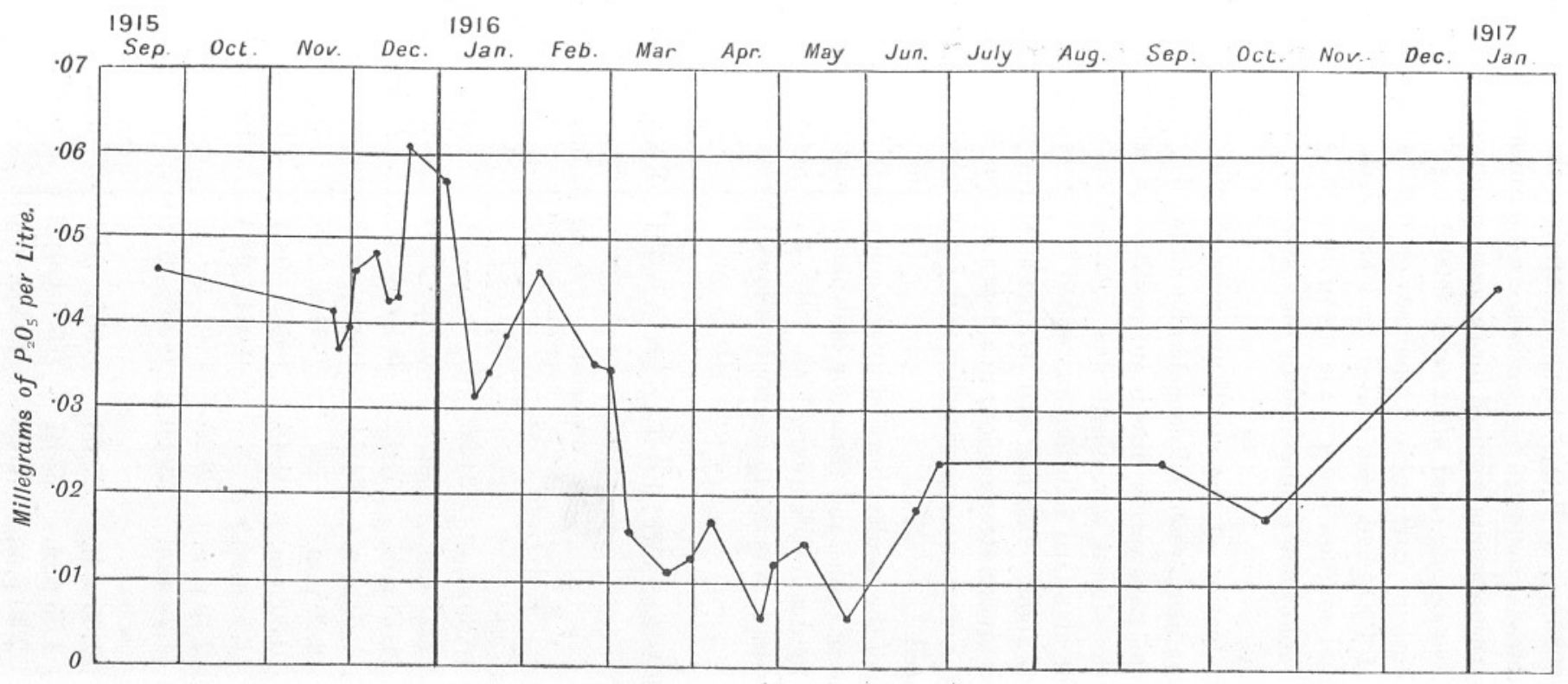

Phosphates In Water at Knap Buoy, Plymouth Sound.

엉 
paper was $0.0036 \mathrm{mg}$. of $\mathrm{P}_{2} \mathrm{O}_{5}$. A repurification of the iron, acids, alkali and water reduced it to $0.0026 \mathrm{mg}$., and a second purification to $0.0021 \mathrm{mg}$. The blank on the amounts required for the estimation of total phosphorus was at first $0.0066 \mathrm{mg}$. and afterwards $0.0061 \mathrm{mg}$. The blanks were determined both by carrying out analyses on distilled water, to which $0.0300 \mathrm{mg}$. of $\mathrm{P}_{2} \mathrm{O}_{5}$ had been added, and also with small amounts of water, the final solution being made up to $10 \mathrm{ccm}$. and compared in a special small colorimeter tube holding only $10 \mathrm{ccm}$. The results agreed excellently.

The determination of the small amounts of phosphoric acid found during the summer presented considerable difficulty. Making the final volume $10 \mathrm{ccm}$. gave rather discordant results, and it was subsequently found that the closest agreement was obtained between duplicates if enough of the standard solution was added to the sample to bring the content up to about $0.035 \mathrm{mg}$. of $\mathrm{P}_{2} \mathrm{O}_{5}$ per litre, the final volume being $50 \mathrm{ccm}$. This gives a strong colour in a depth of $40 \mathrm{~mm}$. and at the same time avoids the errors which arise when very small volumes of liquid are to be manipulated.

The whole of the results obtained by the colorimetric method are given in the following table, and those for phosphoric acid are plotted in the curve; the figures for February 17th, 1915, have not been used in this case as the sample was by an oversight allowed to stand unsterilised for six days.

\section{SURFACE SAMPLES TAKEN AT THE KNAP BUOY.}

$\begin{array}{lll}\text { Phosphates. } & \mathrm{P}_{2} \mathrm{O}_{5} \mathrm{mg} \text {. per litre. } & \begin{array}{c}\text { Total } \mathrm{P} \\ \text { calculated } \\ \text { to } \mathrm{P}_{2} \mathrm{O}_{5} \\ \text { Date. }\end{array} \text { G.M.T. } \\ \text { S. per litre. }\end{array}$

\section{5}

\begin{tabular}{|c|c|c|c|c|c|}
\hline Sept. 21 & 10.30 a.m. & $34 \cdot 96$ & - & $0 \cdot 046$ & - \\
\hline Nov. 24 & 11.35 a.m. & $34 \cdot 78$ & $0.042, \quad 0.041$ & $0 \cdot 0415$ & - \\
\hline , 26 & 11.45 a.m. & $34 \cdot 43$ & $0.040, \quad 0.034$ & $0 \cdot 037$ & - \\
\hline , 29 & 11.10 a.m. & $34 \cdot 14$ & $0.040, \quad 0.037$ & $0 \cdot 0385$ & - \\
\hline Dec. 2 & 12.20 p.m. & - & $0 \cdot 0484,0 \cdot 0435$ & $0 \cdot 0460$ & - \\
\hline 9 & 10.30 a.m. & $31 \cdot 46$ & $0 \cdot 049, \quad 0 \cdot 047$ & $0 \cdot 048$ & - \\
\hline 13 & 11.30 a.m. & - & $0.044, \quad 0.041$ & $0 \cdot 0425$ & 一 \\
\hline,$\quad 16$ & 12.10 p.m. & $26 \cdot 20$ & - & $0 \cdot 043$ & - \\
\hline $\begin{array}{l}, \quad 20 \\
1916\end{array}$ & 11.25 a.m. & $29 \cdot 69$ & $0 \cdot 058, \quad 0 \cdot 064$ & $0 \cdot 061$ & 一 \\
\hline Jan. 3 & 11.35 a.m. & $25 \cdot 66$ & $0.057, \quad 0 \cdot 057$ & $0 \cdot 057$ & 一 \\
\hline , 14 & 1.55 p.m. & $33 \cdot 87$ & $0 \cdot 0318,0 \cdot 0316$ & 0.0317 & - \\
\hline,$\quad 18$ & 2.30 p.m. & $33 \cdot 93$ & $0 \cdot 0336,0 \cdot 0348$ & $0 \cdot 0342$ & - \\
\hline
\end{tabular}




\begin{tabular}{|c|c|c|c|c|c|}
\hline Date. & G.M.T. & S. ${ }^{P h}{ }^{\text {. }}$ & $\begin{array}{l}\text { hates. } \mathrm{P}_{2} \mathrm{O}_{5} \text { mig. per } \\
\text { Found in duplicates. }\end{array}$ & $\begin{array}{l}\text { itre. } \\
\text { Mean. }\end{array}$ & $\begin{array}{l}\text { Total P } \\
\text { calculated } \\
\text { to } \mathrm{P}_{2} \mathrm{O}_{5}\end{array}$ \\
\hline Jan. 24 & 11.20 a.m. & $33 \cdot 42$ & $0 \cdot 0378,0 \cdot 0391$ & $0 \cdot 0384$ & - \\
\hline Feb. 5 & 12.30 p.m. & $31 \cdot 58$ & $0 \cdot 0507,0 \cdot 0414$ & $0 \cdot 0460$ & - \\
\hline,$\quad 17$ & 10.45 a.m. & - & $0 \cdot 0190,0 \cdot 0190$ & $(0 \cdot 0190)$ & $0 \cdot 0323$ \\
\hline ,, 25 & 11.0 a.m. & $33 \cdot 30$ & $0 \cdot 0371,0 \cdot 0343$ & $0 \cdot 0357$ & - \\
\hline Mar. 1 & 11.40 a.m. & $33 \cdot 82$ & - & $0 \cdot 0350$ & $0 \cdot 039$ \\
\hline , 8 & 11.15 a.m. & $34 \cdot 54$ & $0 \cdot 0201,0 \cdot 0115$ & & - \\
\hline ", 21 & 11.50 a.m. & $4 \cdot 54$ & $0 \cdot 0101,0 \cdot 0122$ & & $0 \cdot 050$ \\
\hline , 29 & 11.45 a.m. & $32 \cdot 18$ & $04,0 \cdot$ & 126 & $0 \cdot 045$ \\
\hline April 6 & 11.55 a.m. & $34 \cdot 40$ & $0 \cdot 0160,0 \cdot 0180$ & 70 & $0 \cdot 016$ \\
\hline , 24 & 11.10 a.m. & $34 \cdot 40$ & - & & - \\
\hline , 28 & - & $34 \cdot 40$ & $0 \cdot 0117,0 \cdot 0124$ & $0 \cdot 0120$ & 0.035 \\
\hline May 9 & $10 \cdot 50$ a.m. & & 130 & $0 \cdot 0144$ & $0 \cdot 046$ \\
\hline,$\quad 24$ & 11.45 a.m. & $34 \cdot 60$ & $53,0 \cdot 0064$ & & - \\
\hline June 19 & 10.45 a.m. & $34 \cdot 90$ & $0 \cdot 0185,0 \cdot 0184$ & $0 \cdot 0184$ & $0 \cdot 036$ \\
\hline,,$\quad 27$ & 11.45 a.m. & - & $0 \cdot 0230,0 \cdot 0248$ & 0.0239 & $0 \cdot 038$ \\
\hline Sept. 13 & noon & - & $0.0277,0.0198$ & & $0 \cdot 024$ \\
\hline $\begin{array}{c}\text { Oct. } 19 \\
1917\end{array}$ & 10.45 a.m. & $33 \cdot 93$ & $0 \cdot 0194,0 \cdot 0155$ & $0 \cdot 0174$ & $0 \cdot 029$ \\
\hline Jan. 10 & 12.30 p.m. & $33 \cdot 62$ & $0 \cdot 0435,0 \cdot 0448$ & $0 \cdot 0442$ & $0 \cdot 049$ \\
\hline
\end{tabular}

In the first place it is clear that the results given in the previous paper which were obtained by precipitating the phosphorus with iron and then weighing as phosphomolybdic anhydride are seriously in error, and it was found that molybdic acid was thrown down at the same time.

The data of the present table show that there is a large seasonal variation, the maximum being more than ten times as large as the minimum. At first it was expected that the curve would agree with that for the phytoplankton inverted, but this is not the case. Miss Lebour* has made counts of the diatoms at the surface, $5 \mathrm{fthms.}$ and $7 \mathrm{fthms}$. on 330 samples taken on 110 days at the Knap Buoy from September 21, 1915, to September 18, 1916. The average number in $1 \mathrm{ccm}$. for October, 1915, was 17, and in November 9, while in December and in January, February and March, 1916, there were only one or two. The maximum number for the year, 38, occurred in April, 1916, the high value being due to the last week of the month, 45 being counted on the 25th and 137 on the 27th. Then a decline set in, with 30 per cubic centimetre in May and only 9 in June. In July there was a rise to 21 and a secondary

* Lebour, Marie V., M.Sc., " The Microplankton of Plymouth Sound from the Region beyond the Breakwater." This Journal and Volume, p. 133. 
maximum of 31 in August, followed by a fall to 17 in September. The curve shows that the maximum value for phosphates, $0.061 \mathrm{mg}$. of $\mathrm{P}_{2} \mathrm{O}_{5}$ per litre, coincided with the smallest number of diatoms, and also with the shortest days of the year. The phosphates then commenced to fall at once, irregularly at first it is true, to a minimum, of less than onetenth of the maximum, at the end of April, which coincides with the diatom maximum for the year. The number of diatoms fell off at the beginning of May, while the phosphate minimum continued to the last week of the month. At this period, however, the alga Phoocystis appeared in enormous quantities. It was first abundant on April 25, reached its maximum on May 9th and 12th, then declined, and was absent after June 12th. If the decrease in phosphates is to be attributed to their removal by algæ, as the writer considers to be the case, some other factor must be sought in addition to the phytoplankton. This is probably to be found in the larger algæ, such as Fucus, Laminaria and others. Well grown young plants of these are to be found in February, and must by that time have already abstracted considerable quantities of phosphorus from the water. The march of events would then be somewhat as follows. As soon as the young plants of the fixed algæ begin to increase the amount of phosphates in the water falls off, and this decline is further hastened by the sudden increase of diatoms at the end of April. In May the diatoms decrease, but the phosphates are kept at a minimum value by the appearance of Phacocystis, and increase at once when this disappears in June. The want of data for phosphates in July and August prevents a further comparison with the figures for diatoms, but another minimum might be expected in August. Phosphate values are also missing in November and December, 1916, but the records for 1915 show an agreement with what might be expected from the diatom figures, that is, a rise from November to December.

On January 10th, 1917, the amount of phosphates present was very nearly the mean of the first two figures for the month in the previous year.

The Admiralty regulations have made it impossible to obtain water at a distance from the shore. It is by no means improbable that in mid-Channel, beyond the influence of the fixed weeds, the decrease in the phosphates would not be large until much later in the year when the phytoplankton begins to increase.

The last column of the table contains some figures for the total dissolved phosphorus, calculated to $\mathrm{P}_{2} \mathrm{O}_{5}$. It is not claimed that they are accurate, but they certainly show that what may be called for the present " organic phosphorus" is often high even when the phosphates are at a minimum, though it varies from month to month. The figures for June 27th, 1916, and January 10th, 1917, are probably the most 
accurate, and as the two samples were analysed side by side they are fairly comparable. They show that the total phosphorus may be as high in summer as in winter, but that in summer only a very small part of it may be present as phosphoric acid. The analyses as a whole, however, do not allow more to be stated with certainty than that there is a soluble phosphorus compound present other than phosphoric acid, that it is probably not a lower acid of phosphorus owing to the comparative difficulty with which it is oxidised, and that it is probably an organic compound.

The nature and origin of this " organic phosphorus " is, of course, quite unknown. At first it was thought that it might be due to minute organisms which pass through a filter paper, and an attempt was made to filter it out by means of candles such as are used for bacteriological work, but this proved impossible as both Doulton and Chamberland filters gave up a considerable amount of phosphates to distilled water passed through them. It is, however, unlikely that it is due to solid particles, as if iron and a relatively large amount of ammonia are added to sea-water so as to produce a bulky precipitate of hydrates of iron, lime, and magnesium, which would almost certainly entangle and stop any suspended matter, the filtrate from this still shows a considerable amount of phosphate after oxidising.

\section{SUMMARY.}

The amount of phosphoric acid in sea-water off Plymouth was at a maximum of $0.06 \mathrm{mg}$. per litre of $\mathrm{P}_{2} \mathrm{O}_{5}$ at the end of December, 1915, after which it fell irregularly to a minimum of less than $0.01 \mathrm{mg}$., which extended from the last week of April to the latter part of May; it then increased again and in January, 1917, reached the same value as the average for the first part of the month in the previous year.

This seasonal variation is probably to be attributed to the removal of the phosphates from solution, at first by the fixed algæ, and later in the spring by the diatoms and for a short time by Phaocystis. There is also present in sea-water taken near Plymouth another soluble compound of phosphorus which can be converted into phosphoric acid by oxidising agents. 